\title{
APPLICATIONS OF DSGE MODELS IN CENTRAL BANKING: KEY ISSUES EXPLORED DURING RESEARCH WORKSHOP OF THE NATIONAL BANK OF UKRAINE
}

\section{SERGII KIIASHKO}

${ }^{a}$ National Bank of Ukraine

Email: Serhii.Kiiashko@bank.gov.ua

${ }^{b}$ Kyiv School of Economics

Email: skiiashko@kse.org.ua

\begin{abstract}
This paper reviews a research workshop that was held by the National Bank of Ukraine (NBU) in November 2018 on the application of DSGE models in central banking. We summarize the discussion of the advantages and drawbacks of DSGE modeling and potential ways to resolve issues and improve the models. Furthermore, this paper provides guidance on using DSGE models for forecasting and policy analysis.
\end{abstract}

\section{JEL Codes E37, E52, E58}

Keywords macroeconomic models, dynamic stochastic general equilibrium models, monetary policy, forecasting, policy analysis

\section{INTRODUCTION}

Efficient monetary policy is impossible if a central bank is unable to accurately forecast macroeconomic variables and analyze various policy scenarios. For those needs, central banks currently use many classes of economic models of differing complexities based on data and/or theoretical derivations. Dynamic stochastic general equilibrium (DSGE) models are a relatively new and popular class of models (see Nikolaychuk and Sholomnytskyi, 2015) for details on the use of different economic models in central bank policy making.

DSGE models encompass a broad range of models including neoclassical and New Keynesian monetary models that feature many real and nominal frictions. The key distinction of this class of models is that the decisions made by economic agents (households, firms, lenders, government, etc.) are based on assumptions about preferences, information, technologies, etc., and are derived from intertemporal and intratemporal optimization problems. DSGE model forecasts of macroeconomic indicators have proven themselves to be competitive with other econometric and semi-structural models, while their theoretical coherence makes the models suitable for policy experiments.

Nonetheless, as all models are simplifications of reality, DSGE models often cannot capture all the dynamics and relationships between macroeconomic time series. In addition, many economists believe DSGE models are not better in projecting economic performance than some other econometric or semi-structural models, while the development and maintenance of DSGE models is much costlier. Finally, DSGE models were blamed for not having been able to predict the recent financial crisis.

These and other issues raise questions about whether DSGE models are still useful for forecasting and policy analysis at central banks. If they are not, what types of models can surpass them? If they remain useful, what can be done to improve them? Should economists develop more detailed and elaborate models, or will smaller-scale models do a better job? What is the role of DSGE models in the future: 
should central bankers use DSGE models as core models or as supplemental models? The NBU held a workshop in November 2018 to address these and other questions.

\section{DSGE MODELS FOR POLICY ANALYSIS}

Are DSGE models useful for policy analysis? Guido Ascari (University of Oxford and Pavia) started his talk by sharing his opinion on the future of macroeconomics and stating the two principles of economics: "all models are false" but "some models are useful." Guido Ascari is certain that a "good" model exists, however, a model is only good for a particular research question. In his view, economists have been engaged in similar "macro wars" in the past (for example, after the Great Depression or the period of Stagflation) and each time it gave rise to new features in macroeconomic models that made them useful for analysis, forecasting, and policy making. This time is no different, according to Mr. Ascari, and he encouraged participants to avoid useless debates and instead focus on incorporating any missing features into DSGE models, including financial frictions and banking, heterogeneity, bounded rationality, robust control, information, coordination failures, and more.

Mr. Ascari then presented two applications of a state-ofthe-art medium-scale New Keynesian DSGE model (in the spirit of Christiano et al. (2005) or Smets and Wouters (2007): "Business cycles, investment shocks, and the 'Barro-King' curse" (Ascari et al., 2016) and "On the welfare and cyclical implications of moderate trend inflation" (Ascari et al., 2015).

The first paper proposes a way to escape the well-known "Barro-King" curse: models with investment shocks predict a negative correlation between consumption and investment and a weak positive correlation between consumption and output, whereas post-war data suggest a positive correlation between consumption and investment and a strong positive correlation between consumption and output. The reason is that a positive shock to the rate of return on capital incentivizes households to save to invest more. In addition, an increase in the marginal utility of consumption shifts labor supply to the right, raising hours worked and output.

The authors find that the introduction of two realistic features, a "roundabout production" structure and realistic real per capita output growth in neutral and investmentspecific technologies, are sufficient to eliminate the "Barro-King" curse. The introduction of intermediate goods producers decreases the sensitivity of the real marginal cost to changes in factor prices, flattening the New Keynesian Phillips Curve. Trend growth makes firms more forwardlooking when setting prices. Consequently, following a positive shock to the marginal efficiency of investment, the marginal cost does not increase by that much, which leads to a larger and more prolonged increase in output. The latter in turn makes the income effect on consumption stronger overturning the negative substitution effect. As a result, consumption co-moves with investment and has stronger correlation with output.

The second paper focuses on the welfare losses of moderate trend inflation. After the Great Recession, many economists advocated for an increase in the inflation target from 2 to 4 or 5 percent. An argument in favor of such a measure is that it would allow to restore flexibility to lower nominal interest rates and to escape zero lower bounds in future recessions. In addition, as recent literature suggests, the costs of increasing trend inflation are low, and the benefits likely outweigh these costs. This raises the question of whether central banks are right opposing an increase in inflation targets.

Mr. Ascari and his co-authors find that once a "smallscale" model is augmented with several realistic features, the predicted cost of higher trend inflation increases significantly. An increase in trend inflation from 2 to 4 percent implies a $4.3 \%$ decrease of mean consumption and a 3.7\% decrease in non-stochastic steady-state consumption compared to $0.17 \%$ and $0.22 \%$, respectively, in sticky-price models that lack those main features. The authors conclude that wage rigidity is costlier than price rigidity and that the costs of trend inflation are amplified by trend growth, roundabout production, extended borrowing, and shocks to the marginal efficiency of investment.

Jesper Linde (Sveriges Riksbank) opened the NBU's workshop with a presentation titled "DSGE Models: Still Useful in Policy Analysis?". In his view, despite undisputed fundamental flaws and the inability of DSGE macroeconomic models to predict the Great Recession (2008-2009), they will continue to be an important tool for policy analysis and decisions. In addition, Jesper shared his view on how core macro models should be changed, and the list of criteria required for a model to be useful and influential.

Following the unexpected sharp economic decline in 2008, many held the view that DSGE models failed to predict the crisis and, thus, should be abandoned and substituted for alternative approaches. However, others, like Mr. Linde, believe there is nothing wrong with DSGE models, though, the models indeed should be revised to encompass all relevant features: the financial sector, financial frictions, non-linearities, heterogeneity, and other factors.

Mr. Linde agreed that the crisis revealed some severe weaknesses in DSGE modeling, for example, the models could not predict the crisis, especially not in expectation. However, professional forecasters who used alternative forecasting approaches, like Bayesian Vector Autoregression Models (see Linde et al., 2016), also failed to predict the crisis. Mr. Linde noted that policy model specification reflects an active interplay between policymakers and model builders. This was one of the reasons why DSGE models did not feature an elaborated financial system with financial frictions. And, since the prevailing belief among policymakers and model builders was that substantial financial sectors shocks were improbable, the models were unable to predict the crisis.

How should new models be developed? Mr. Linde believes economists should focus on smaller models first to study new mechanisms and to introduce those mechanisms to large-scale core models only after they are understood. In his view, medium-scale DSGE models will dominate at least in the nearest future as they better fit some of the criteria of useful core policy models, such as being in-line with the institutional view, being important in communicating future policies on outcomes today, being relatively accurate at forecasting, and, finally, being simple and transparent enough to be understood by policymakers and maintained when model builders leave.

Ahn Nguyen (Bank of Lithuania) presented a joint project with Aurelija Proskute titled "Lithuania, Euro Area, and global economy". The project aims to study the transmission mechanism of the European Central Bank's monetary policy to the Lithuanian economy. The model features four 
geographical regions (Lithuania, the rest of the euro area, the US, and the rest of the world), the Monetary Union (monetary policy reacts to the union's economic conditions), and intermediate goods. The regions are connected via trade and financial links to account for macroeconomic spillover.

Oleksandr Faryna (National Bank of Ukraine) presented a paper called "Short-term costs of disinflation in a closed economy and a small open economy" (with Magnus Jonsson and Nadiia Shapovalenko). Since inflation targeting has become a popular monetary policy regime, questions have emerged about the costs of disinflation - the reduction in long-term inflation. The existing literature is focused on closed economies (see Ascari et al., 2013), while empirical papers studying open economies have mixed results, so the paper contributes by studying the costs of disinflation (measured as a sacrifice ratio) for a small open economy and comparing the results with a benchmark closed economy.

The study finds that disinflation in a small open economy is costlier than in a closed economy. Following an increase in the real interest rate, the real exchange rate appreciates, causing a decrease in net exports which makes the output loss larger for a small open economy. An optimal policy that minimizes the central bank loss function should focus on output stabilization and not on stabilizing the exchange rate.

In addition, Mr. Faryna studies optimal policy rules in an environment with imperfect credibility. He concludes that the costs of disinflation can increase substantially under this assumption. An optimal policy in this case should pay more attention on inflation expectations rather than output stabilization. In addition, the pre-announcement of a new inflation target can decrease the sacrifice ratio especially in a model with imperfect credibility.

\section{CHALLENGES IN DEVELOPING AND SOLVING DSGE MODELS}

Despite the numerous benefits of using DSGE models for policy analysis and policy making, not all economists are convinced that this class of models will dominate in central banks. One such example is Jaromír Beneš, independent consultant and formerly of the International Monetary Fund (IMF) and the Czech National Bank (CNB). He presented a talk titled "Beyond traditional DSGEs in real-world policy making". The speaker was more pessimistic than other workshop participants about the application of DSGE models in forecasting and policy analysis.

In his view, even though DSGE models are useful in policy analysis, the transition from QPM (smaller-scale semistructural models) to DSGE models does not necessarily constitute progress. One of the greatest drawbacks of DSGE models is the time dimension and uncertainty about the future. In the speaker's point of view, in the real world, people think of the future, form expectations, and make their choices differently than how economists model those decisions. For example, the Lehman Brothers bankruptcy led to the reevaluation of investment models, more conservatism, and a general disengagement from risky activity. This behavior clearly suggests an aversion to this kind of uncertainty rather than merely an increase in exposure to risk, indicating the non-ergodicity of the real world - a feature that conventional DSGE models miss. In Mr. Beneš' point of view, these types of issues are added to DSGE models as an afterthought which makes these models less consistent externally.
The other shortcoming of DSGE models, according to Mr. Beneš, is intertemporal optimization. While intratemporal optimization is the "greatest blessing of DSGEs," intertemporal optimization ignores many things like fundamental uncertainty and the non-ergodicity of the real world. To resolve this issue, the speaker proposes considering an optimization problem over a finite horizon with "scrap value" left after the planning horizon.

Marcin Kolasa (Narodowy Bank Polski) discussed challenges in forecasting using small open economy DSGE models. The talk was based on two papers: "Does the foreign sector help forecast domestic variables in DSGE models" with (Kolasa and Rubaszek, 2018), and "Exchange rate forecasting with DSGE models” with (Ca'Zorzi and Rubaszek, 2017).

Generally, there is a consensus that forecasts based on DSGE models are as accurate as forecasts based on time series models or professional forecasters. However, most studies that support this point of view are based on the US economy and closed economy set-up whereas central banks predominantly use open economy models. In the first paper, Marcin and his co-author study the forecasting performance of open economy DSGE models (based on Justiliano and Preston, 2010) in comparison to a New Keynesian closed economy benchmark. The authors use long period data from Australia, Canada, and the United Kingdom. The main finding of the paper is that small open economy models not only fail to outperform the closed economy benchmark models, but even have worse forecasts for important domestic variables.

Marcin concludes that even though there are potential gains from using larger models with richer specification and more observables, these models in fact can produce less accurate predictions due to misspecification (particularly, international competitiveness block), larger estimation forecast errors, or wrong priors.

A challenge in international economics is the poor performance macro models have in explaining exchange rate dynamics; even naïve random walk models tend to outperform them. Recent developments in empirical literature suggest, however, that the real exchange rate can be better described by a mean-reverting process. The second paper is, thus, devoted to the question of whether modern open-economy DSGE models that account for this feature of the exchange rate can be more useful than the simplest random walk process. The results are mixed.

The good news is that state-of-the-art open economy DSGE models consistently outperform random walk in forecasting real exchange rates over the mediumterm. In addition, their performance is comparable to an autoregressive process and a Bayesian vector autoregressive process. On the downside, however, DSGE models fail to predict nominal exchange rates because they struggle to forecast the co-movement between domestic and foreign prices. To beat the random walk in forecasting both real and nominal exchange rates, models must hold true three principles: ignore high exchange rate volatility, exploit the mean reversion of real exchange rates, and account for the co-movement of international prices.

Guillermo Hausmann-Guil (Bank of Lithuania and Vilnius University) presented his paper titled "Solving recursive macroeconomic models around the ergodic steady state". Most DSGE models are solved using local (perturbation) 
methods, e.g., approximating the value and policy around the steady state. However, this approach has some limitations: it requires a well-defined steady state, there is a certainty equivalence up to the first order, and it cannot deal with incomplete markets.

The speaker introduced a method to resolve the aforementioned issues. That approach also allows the models to be extended by adding a continuum of ex-ante identical agents that are heterogeneous ex-post, idiosyncratic and aggregate risk, and portfolio choice.

Alon Binyamini (Bank of Israel) discussed ways to fit non-stationary data to standard models (including DSGE) that rely on stationarity assumptions like a balanced growth path and more.

\section{DSGE MODELS WITH FINANCIAL FRICTIONS}

DSGE models were blamed for being unable to predict the financial crisis in 2008. As a result, macroeconomists started to incorporate banking and financial sectors with various financial frictions to DSGE models to make the models more useful in predicting future financial crises and to be able to use these models to study efficient macroprudential policies.

One such model is outlined in a paper by Janius Karmelavicius (Bank of Lithuania) titled "Bank credit and money creation in a DSGE model of a small open economy" (with Tomas Ramanauskas (Bank of Lithuania)). In this project, the authors focus on the fact that the banking system not only reallocates real resources in an economy, but also is an important driver of money growth and, hence, inflation dynamics.

Mr. Karmelavicius considers a small open economy model within a monetary union with rigid prices and a bank with an explicit balance sheet. The model is calibrated to match Lithuania's economic data. The authors show that the financial system is highly elastic, meaning that banks can extend credit irrespective of accumulated resources or the need to increase nominal interest rates. In the extension of the model, among other features, the authors consider housing, mortgages and endogenous mortgage defaults, multi-period loans etc., and analyze the efficiency of different prudential policy tools (LTV tightening, capital requirements, etc.) in minimizing default risks.

Another example is a paper by Ales Marsal (National Bank of Slovakia) titled "Trend inflation and asset pricing in a DSGE model" (with Lorant Kaszab (MNB) and Katrin Rabitch (Vienna University of Economics and Business)). This paper contributes to the discussion of the so-called "bond premium puzzle" - the fact that the term structure of interest rates is upward sloping which is hard to explain using conventional models and assumptions.

The authors show that the Rudebusch and Swanson (2012) model ability to explain large and volatile term premium and key macroeconomic variables at the same time relies heavily on an assumption of zero trend inflation. They show that once this assumption is added to the model, business cycle and bond price dynamics become implausible. Mr. Marsal also discussed several extensions of the model which can partially alleviate this issue.

\section{DSGE MODELS IN MONETARY POLICY DECISION MAKING}

Are DSGE models useful for forecasting and decisionmaking purposes and how are these activities organized at different central banks? These and other related questions were discussed in a separate session.

Karel Musil (Czech National Bank) discussed a core projection DSGE model used by the Czech National Bank (CNB). The speaker started his talk by highlighting that the CNB is one of the most transparent central banks in the world. The CNB not only publishes most details on its forecasts and macroeconomic projections, but also reveals its core model with coefficients and codes to allow outsiders to replicate the projections.

The CNB began developing its DSGE model (called " $\mathrm{g3}$ ") in 2007 , and in 2008 , it replaced the quarterly projection model previously used as the CNB's main forecasting tool. g3 is a small open economy DSGE model that captures the main characteristics of the Czech economy. The model features standard frictions like Calvo price settings, habits in consumption behavior, capital formation, and more. It has a detailed structure of consumption prices, including regulated prices. Monetary policy is modeled as a forward-looking inflation targeting rule. Some other features incorporated to the model are balanced growth path, sector-specific price trends, trade openness, imperfect exchange rate passthrough, import intensity of exports, etc.

The CNB's Forecasting and Policy Analysis System (FPAS) is comprised of near-term forecasting (nowcasting, short-term projections, etc.) and medium-term forecasting performed by the g3 DSGE model. The CNB forecasts in four major steps: 1) identification and interpretation of initial conditions; 2) projection simulation and judgement; 3) scenario analysis and decomposition of forecast dynamics; 4) communication. Mr. Musil noted that the forecast is never a mechanical procedure; it requires expert judgement. Nevertheless, the speaker is certain that the DSGE model is useful and practical for forecasting, policy analysis, and decision-making.

The CNB plans to expand the existing model by elaborating the external block to improve the outlook for external variables and by adding oil and energy prices, credit-constrained households, investment dynamics, the labor market, and more.

Annukka Ristiniemi (Sveriges Riksbank) presented DSGE-based forecasting practices at the Swedish central bank. According to Ms. Ristiniemi, the Riksbank's DSGE model (called "Ramses II") is the bank's main projecting and scenario tool. However, they plan to switch to a new model soon to better capture international transmission, a challenge the current model face.

Ramses II is based on models by Christiano et al. (2010) and Adolfson et al. (2013). It is a small open economy model with a foreign sector that follows the vector autoregressive process. The model's features include sticky prices, habits in consumption, unemployment, financial frictions, variable capital utilization and adjustment costs, monetary policy rules, etc. 
The Riksbank's forecasts are based on revisions of previous predictions, meaning the forecasting team compares the outcomes from Ramses II with actual values, uses the model to identify the innovations that explain errors, and adjusts the forecast accordingly. In addition, the forecasting procedure uses inputs from other divisions such as nowcasts, foreign and financial forecasts, and others. According to Ms. Ristiniemi, Ramses II is a good core model; Iversen et al. 2016 found the DSGE forecasting performance is even better than final judgment forecasts.

Nonetheless, according to Ms. Ristiniemi, models like Ramses II struggle to account for foreign spillover. Other challenges include unconventional monetary policy and trend and exchange rate modelling. To address these issues, developers at the Riksbank are working on a new core model. The model is built on Ramses I (a previous version of Ramses II) and is focused on international linkages featuring a two-country small open-economy model with global correlated shocks and exports oriented towards investment.

Jacek Suda (Narodowy Bank Polski) discussed the role DSGE models play in forecasting at the National Bank of Poland. The first version of the model (called SoePL) was launched in 2007 and was based on Adolfson et al. (2007). Since then, the model has undergone five or six major revisions. SoePL is a New Keynesian small open economy model with floating exchange rate featuring price and wage stickiness, elaborated labor and capital markets, an exogenous foreign sector, taxes, inflation targeting etc. The most recent update extended the model to include heterogenous households, public consumption and investment, fiscal rules, and a non-zero debt-to-GDP ratio.

Even though the model's main task is forecasting, SoePL's forecasts are not announced publicly. Instead, the National Bank of Poland uses NECMOD model for its official published forecasts. In Mr. Suda's point of view, the DSGE forecasts can predict some turning points and medium-term trends, however, its forecasts often miss, and their accuracy is insufficient. Expert judgement is therefore required.

Ginters Buss (Latvijas Banka) shared his experience of working with DSGE models and their applications at Latvijas Banka. The bank uses smaller models for policy analysis only and a main model for policy simulations and forecasting. The first group includes a model with banks and housing for Latvia, a model with quantitative easing for the euro area, and a global model for Latvia, the rest of the euro area, the US, and the rest of the world. Latvijas Banka's main DSGE model was developed in several steps. The developers started with a small open economy model based on Christiano et al. (2010) featuring monetary union and financial accelerator (see Buss, 2014). At the next step search and matching frictions in the labor market were added to the model (Buss, 2015). In a recent version of the model (Buss, 2017), among other changes, labor market block was replaced with alternating-offer wage bargaining as in Christiano et al. (2016).
According to Mr. Buss, DSGE models were used to simulate tax reforms in Latvia, the overheated labor market in Latvia, the housing bubble bursting in Sweden and its possible effect on Latvia's economy, the consequences of Brexit, what if Latvia was not a member of the Euro Area, the impact of a fiscally less responsible government, and other policy scenarios.

In the speaker's point of view, forecasting using a DSGE model is complicated, specifically for a tiny small open economy like Latvia. For example, a large investment like the purchase of an airplane would represent a substantial spike in investment. The forecasts are relatively robust, but insufficient for forecasting. Therefore, model-based forecasts are used only as a base for any final forecasts as they require additional interpretation and judgement.

In the future, developers at Latvijas Banka plan to augment their DSGE model with fiscal sector and banking/ financial sector to account for public consumption and investment, public debt, transfers, fiscal rules, long-term rates, long-term loans.

Finally, Shalva Mkhatrishvili (National Bank of Georgia) discussed the National Bank of Georgia's (NBG) use of macroeconomic models for monetary policy. The NBG's Forecasting and Policy Analysis System is based on a core semi-structural model, short-term forecasting models (error-correction model, ARIMA, and others), and additional satellite models. The NBG uses DSGE models for educational purposes and for cross-checking.

\section{CONCLUDING REMARKS}

Dynamic stochastic general equilibrium (DSGE) modeling has become a widely used tool for policy analysis and forecasting at central banks. The DSGE approach allows users to evaluate the consequences of various policy measures while the quality its predictions of macroeconomic dynamics is competing with other forecasting models. Nonetheless, the views of economists on the DSGE approach vary, as there are many challenges in developing and solving DSGE models.

In attempting to create models that replicate more empirical relationships between macroeconomic variables, economists often introduce too many ingredients to the model, making it less tractable but not always more useful or accurate. In addition, when conventional assumptions do not lead to desirable patterns consistent with empirical observations, economists are tempted to incorporate "exotic" assumptions. Although these assumptions help bring the models closer to the data, they likely do not reflect real economic processes, there is a risk that these assumptions won't work well if macroeconomic policies or conditions change. Thus, to improve DSGE models, instead of simply enlarging models, economists would do well to rethink conceptual macroeconomic insights to be able to use better assumptions. 


\section{REFERENCES}

- Adolfson M., Laséen S., Lindé J., Villani M. (2007). Evaluating An Estimated New Keynesian Small Open Economy Model. Working Paper Series, No. 203, Sveriges Riksbank (Central Bank of Sweden).

- Adolfson M., Laséen S., Christiano L., Trabandt M., Walentin K. (2013). Ramses II - Model Description. Occasional Paper Series, No. 12, Sveriges Riksbank (Central Bank of Sweden).

- Andrle M., Hledik T., Kamenik O., Vlcek J. (2009). Implementing the New Structural Model of the Czech National Bank. Working Papers, No. 2009/2, Czech National Bank.

- Ascari G., Phaneuf L., Sims E. (2015). On the Welfare and Cyclical Implications of Moderate Trend Inflation. Working Papers, No. 21392, National Bureau of Economic Research, Inc.

- Ascari G., Phaneuf L., Sims E. (2016). Business Cycles, Investment Shocks, and the "Barro-King" Curse. Working Papers, No. 22941, National Bureau of Economic Research, Inc. https://doi.org/10.3386/w21392

- Ascari G., Ropele T. (2013). Disinflation Effects in a MediumScale New Keynesian Model: Money Supply Rule Versus Interest Rate Rule. European Economic Review, Vol. 61, (C), pp. 77-100. https://doi.org/10.1016/j.euroecorev.2013.03.004

- Buss G. (2014). Financial Frictions in a DSGE Model for Latvia. Working Papers, No. 2014/02, Latvijas Banka.

Buss G. (2015). Search-and-Matching Frictions and Labour Market Dynamics in Latvia. Working Papers, No. 2015/04, Latvijas Banka.

- Buss G. (2017). Wage Formation, Unemployment and Business Cycle in Latvia. Working Papers, No. 2017/01, Latvijas Banka.

- Ca'Zorzi M., Kolasa M., Rubaszek M. (2017). Exchange Rate Forecasting with DSGE Models. Journal of International Economics, Vol. 107, (C), pp. 127-146. https://doi.org/10.1016/j.jinteco.2017.03.011

- Christiano L.J., Eichenbaum M., Evans C. (2005). Nominal Rigidities and the Dynamic Effects of a Shock to Monetary Policy. Journal of Political Economy, Vol. 113, No. 1, pp. 1-45. http://dx.doi.org/10.1086/426038
- Christiano L.J., Eichenbaum M., Trabandt M. (2016). Unemployment and Business Cycles. Econometrica, Vol. 84, pp. 1523-1569. https://doi.org/10.3982/ECTA11776

- Christiano L.J., Trabandt M., Walentin K. (2010). DSGE Models for Monetary Policy Analysis. Working Papers, No. 16074, National Bureau of Economic Research, Inc. https://doi.org/10.3386/w16074

- Iversen J., Laséen S., Lundvall H., Söderström U. (2016). Real-Time Forecasting for Monetary Policy Analysis: The Case of Sveriges Riksbank. Working Paper Series, No. 318, Sveriges Riksbank (Central Bank of Sweden).

- Justiniano A., Preston B. (2010). Monetary Policy and Uncertainty in an Empirical Small Open-Economy Model. Journal of Applied Econometrics, Vol. 25, No. 1, pp. 93-128. https://doi.org/10.1002/jae.1153

- Kolasa M., Rubaszek M. (2018). Does the Foreign Sector Help Forecast Domestic Variables in DSGE Models? Working Papers, No. 282, Narodowy Bank Polski.

- Lindé J., Smets F., Wouters R. (2016). Challenges for Central Banks' Macro Models. Working Paper Series, No. 323, Sveriges Riksbank (Central Bank of Sweden).

- Nikolaychuk S., Sholomytskyi Y. (2015). Using Macroeconomic Models for Monetary Policy in Ukraine. Visnyk of the National Bank of Ukraine, No. 233, pp. 54-64. https://doi.org/10.26531/vnbu2015.233.054

- Ramanauskas T., Karmelavicius J. (2018). Bank Credit and Money Creation in a DSGE Model of a Small Open Economy. Working Paper Series, No. 52, Bank of Lithuania.

- Rudebusch G., Swanson E. (2012). The Bond Premium in a DSGE Model with Long-Run Real and Nominal Risks. American Economic Journal: Macroeconomics, Vol. 4, No. 1, pp. 105-143. https://doi.org/10.1257/mac.4.1.105

- Smets F., Wouters R. (2007). Shocks and Frictions in US Business Cycles: A Bayesian DSGE Approach. American Economic Review, Vol. 97, No. 3, pp. 586-606. https://doi.org/10.1257/aer.97.3.586 